\title{
Human epidermal growth factor receptor 2 protein expression between primary breast cancer and paired asynchronous local-regional recurrences
}

\author{
JIANJIE XIANG ${ }^{1}$, XIAOCHAN PAN ${ }^{1}$, JING XU ${ }^{1}$, XIANHUA FU ${ }^{1}$, \\ DONGPING WU ${ }^{2}$, YU ZHANG ${ }^{1}$, LI SHEN $^{1}$ and QICHUN WEI ${ }^{1}$ \\ ${ }^{1}$ Department of Radiation Oncology, Ministry of Education Key Laboratory of Cancer Prevention and Intervention, \\ The Second Affiliated Hospital, Zhejiang University School of Medicine, Hangzhou 310009; \\ ${ }^{2}$ Department of Oncology, Shaoxing Hospital, Zhejiang, P.R. China
}

Received June 25, 2011; Accepted August 4, 2011

DOI: $10.3892 /$ etm.2011.335

\begin{abstract}
Knowledge concerning concordance of epidermal growth factor receptor 2 (HER2) expression between primary breast cancers and asynchronous local-regional recurrences is sparse. Receptor characteristics could be altered with time and may be affected by anticancer treatment. It remains uncertain whether recurrences have the identical or similar HER2 receptor expression pattern as the primary breast cancer. The aim of the present study was to evaluate whether HER2 is stable during the process of recurrence. Expression of HER2 was investigated immunohistochemically in paired samples of primary breast cancers and corresponding asynchronous local-regional recurrences $(n=35)$. HER2 expression was scored as $0,1+, 2+$ or $3+$. HER2 overexpression $(2+$ or $3+)$ was found in $48.57 \%(17 / 35)$ of the primary breast cancers and $45.71 \%(16 / 35)$ of the corresponding local-regional recurrences. A concordance of HER2 overexpression between the primary lesions and matching regional recurrences was observed in $85.71 \%$ of the breast cancer cases. Five out of the 35 paired samples $(14.28 \%)$ were discordant. Only 3 patients who had 2+ HER2 expression in the primary tumors showed HER2 down-regulation ( 0 or $1+$ ) in the recurrences, while the HER 2 score in 2 patients changed oppositely. Moreover, all of the cases with $3+$ HER 2 staining in the primary lesions retained HER2 overexpression in the recurrences. The HER2 is commonly expressed in breast cancer, and its expression in the primary tumors and the corresponding recurrences was concordant in the majority of the cases. As the receptor
\end{abstract}

Correspondence to: Dr Qichun Wei, Department of Radiation Oncology, Ministry of Education Key Laboratory of Cancer Prevention and Intervention, the Second Affiliated Hospital, Zhejiang University School of Medicine, Jiefang Road 88, Hangzhou 310009, P.R. China

E-mail: qichun_wei@zju.edu.cn

Key words: breast cancer, HER2, recurrence, receptor overexpression expression may lose or gain in recurrences at a probability of approximately $10 \%$, assessment of the receptor status in recurrences is still encouraged.

\section{Introduction}

Breast cancer represents the most common malignancy affecting women in developed countries, with more than 200,000 new cases diagnosed yearly in the US (1). Moreover, the incidence rates have increased rapidly in previously lowincidence areas, such as China (2), partly due to changes in life style and professional habits, as well as the progression of urbanization.

The last decade has witnessed significant achievements in the management of advanced breast cancer, including the introduction of novel chemotherapeutic agents $(3,4)$, the use of aromatase inhibitors in post-menopausal women $(5,6)$, and the benefits derived from molecular-targeted agents, e.g., trastuzumab $(7,8)$ and lapatinib $(9)$, in patients with epidermal growth factor receptor 2 (HER2)-overexpressing tumors. Despite aggressive multidisciplinary treatment approaches, the prognosis of metastatic breast cancer remains poor, with a median survival of 20 months (10).

HER2, a member of the epidermal growth factor receptor family, is a major target for molecular-targeted therapy in breast cancer. HER2 locates at human chromosome 17q11.2-12, encoding a transmembrane tyrosine kinase that is composed of three distinct regions: an extracellular region containing a ligand-binding domain, a transmembrane domain and an intracellular region harboring a tyrosine kinase domain. Ligand binding leads to receptor dimerization, autophosphorylation and subsequent activation of intrinsic tyrosine kinase activity. Activation of HER2 receptors initiates a series of downstream signaling pathways that regulate various cellular functions, including cell proliferation, apoptosis, angiogenesis and motility.

Although HER2 is not expressed on the cell surface of many normal tissues (11), HER 2 gene amplification and protein overexpression are present in 20-30\% of breast cancers (12-14). HER2 receptor has become an important target for targeted 
cancer therapy with trastuzumab (Herceptin $\left.{ }^{\circledR}\right)$. Trastuzumab, a humanized monoclonal antibody (15), has revolutionized therapy for patients with metastatic breast cancers. Studies have indicated that trastuzumab is particularly effective in the treatment of HER2-positive metastatic breast cancer.

Overexpression of HER2 has been identified in human breast cancers (12-14). Although similar HER2 receptor expression between primary breast cancers and metastatic lymph nodes has also been reported (16-18), there are only a few reports regarding the comparison of the HER2 status between the primary breast cancer and the distant metastatic lesions $(19,20)$. To date, the literature regarding the concordance of HER2 receptor expression between primary and local-regional recurrences is sparse. It remains uncertain whether recurrences have the identical or similar HER2 receptor expression pattern as the primary breast cancer.

Receptor overexpression, together with a similar expression in both primary tumors and disseminated lesions, is considered necessary for the success of targeted therapy, particularly targeted nuclide radiotherapy. In receptor-mediated tumor targeting nuclide radiotherapy, tumor cells are killed with delivered radiation, and therapeutic efficiency is mainly dependent on the receptor expression (21). However, in most studies, samples for analysis are usually obtained from the primary lesion, and the status of the targeted molecules is determined based only on the primary tumor. In the present study, the expression of HER2 was investigated immunohistochemically in a series of primary breast cancer samples and corresponding local-regional recurrent lesions.

\section{Materials and methods}

Patients and samples. Thirty-five breast cancer patients with formalin-fixed, paraffin-embedded tumor samples available from untreated primary tumors and later clinically manifested local or regional recurrent tumor deposits were identified in the specimen database of the Department of Pathology, Second Affiliated Hospital Zhejiang University and Shaoxing Hospital. The time period between surgical removal of the primary tumor and surgery or biopsy of the recurrent tumor lesion ranged from 5 to 61 months (median 20). Two separate metastatic lesions (chest wall and supraclavicular) were available for this study from 2 patients. The site of recurrence was chest wall in 32 cases, supraclavicular recurrence in 1 case and 2 were both chest wall and supraclavicular recurrences. The patients were diagnosed between the years 1998 and 2010, and the patient age at diagnosis ranged from 31 to 74 years (median 51). Twenty-five (71.4\%) cases were invasive ductal carcinomas, 1 (2.8\%) was invasive lobular carcinoma, 2 (5.7\%) were mucinous adenocarcinomas, $6(17.1 \%)$ were carcinoma simplex and 1 (2.8\%) was medullary cancer. Six cases had no lymph node metastasis, 9 cases had 1-3 metastatic lymph nodes, 15 cases had $\geq 4$ metastatic lymph nodes, and the lymph node status was not available in the other 5 cases. All patients had no distant metastasis at the time of diagnosis.

HER2 staining. The study was carried out under approval of the Institutional Review Board in accordance with the Declaration of Helsinki. The tissues were fixed in $4 \%$ buffered formalin, processed and embedded in paraffin. Sections
Table I. HER2 scores for the analyzed primary breast cancers and the paired asynchronous local-regional recurrences $(n=35)$.

\begin{tabular}{llccc}
\hline & \multicolumn{4}{c}{$\begin{array}{c}\text { Local-regional recurrences } \\
\text { HER2-scores }\end{array}$} \\
\cline { 2 - 5 } & 0 & $1+$ & $2+$ & $3+$ \\
\cline { 2 - 5 } & & & & \\
Primary tumor & 7 & 0 & 0 & 0 \\
0 & 2 & 7 & 1 & 1 \\
$1+$ & 0 & 3 & 3 & 2 \\
$2+$ & 0 & 0 & 5 & 4 \\
$3+$ & & & &
\end{tabular}

0 , completely negative staining; $1+$, faint perceptible staining of the tumor cell membranes; $2+$, moderate staining of the entire tumor cell membranes; $3+$, strong circumferential staining of the entire tumor cell membranes creating a fishnet pattern.

(4- $\mu \mathrm{m})$ were then cut and deparaffinized in xylene and hydrated through graded concentrations of ethanol to distilled water. The HER2 immunohistochemical staining was carried out as previously described (22). After deparaffinization, the sections were incubated in methanol and hydrogen peroxide for $30 \mathrm{~min}$ to quench the endogenous peroxidase. Antigen retrieval was performed in a waterbath at $98^{\circ} \mathrm{C}, \mathrm{pH} 6.0$ for $40 \mathrm{~min}$. Thereafter, the slides were cooled at room temperature and then washed in distilled water. Immunohistochemical staining was performed using the Elite $\mathrm{ABC}$ kit (Vectastain; Vector Laboratories, Burlingame, CA, USA). Blocking serum was applied for $15 \mathrm{~min}$ followed by incubation with rabbit antihuman c-erbB-2 oncoprotein (code no. A 0485; Dako), diluted 1:350. Sections were then incubated with the biotinylated secondary antibody and were visualized using the peroxidase substrate 3-amino-9-ethyl-carbazole (AEC) (A-5754; Sigma) as chromogen. Finally, the sections were counterstained with Mayer's hematoxylin and mounted.

HER2 scores. HER2 expression was scored using the HercepTest scoring criterion. The HER 2 score was based on a scale where 0 corresponded to tumor cells that were completely negative, 1+ corresponded to faint perceptible staining of the tumor cell membranes, $2+$ corresponded to moderate staining of the entire tumor cell membranes and 3+ was strong circumferential staining of the entire tumor cell membranes creating a fishnet pattern. The Canadian and the Dako HercepTest guidelines were applied, which require $>10 \%$ of the tumor cells to be stained (23). Cytoplasmic staining was considered non-specific and was not included in the scoring. As positive controls, in-house positive control tissue sections were used, as well as positive control sections supplied by Dako. As negative controls, normal tissues were used, which are expected not to express HER2, such as connective tissue observed in the same sections as the tumor cells. In sections of lymph node metastases, lymphocytes and the surrounding capsule of the lymph nodes were used as negative internal controls. 
Table II. Discordant data between the primary lesions and paired recurrences.

\begin{tabular}{|c|c|c|c|c|c|}
\hline Case no. & Primary tumor (HER2) & Date & Metastasis (HER2) & Metastatic site & Date \\
\hline 1 & Negative & August, 2005 & Positive & Chest wall and supraclavicular & April, 2008 \\
\hline 2 & Positive & November, 1998 & Negative & Supraclavicular & May, 2001 \\
\hline 3 & Positive & May, 1999 & Negative & Chest wall & July, 2000 \\
\hline 4 & Negative & February, 2003 & Positive & Chest wall & November, 2004 \\
\hline 5 & Positive & Jamuary, 2003 & Negative & Chest wall & January, 2004 \\
\hline
\end{tabular}

Table III. Major results from the HER2-score analyses of breast cancer $(n=35)$.

HER2-score characteristics

Cases $(\%)$

Primary tumors with $2+$ or $3+$

$17(48.57)$

Local-regional recurrences with $2+$ or $3+$

$16(45.71)$

Unchanged HER2 scores in local-regional recurrences vs. the primary tumors

$30(85.71)$

Changed EGFR scores in local-regional recurrences vs. the primary tumors

$5(14.29)$

Patients who had a score of 0 or $1+$ in primary tumors which changed to $2+$ or $3+$ in local-regional recurrences

$2(5.71)$

Patients who had a score of $2+$ or $3+$ in primary tumors which changed to 0 or $1+$ in local-regional recurrences

$3(8.57)$

A

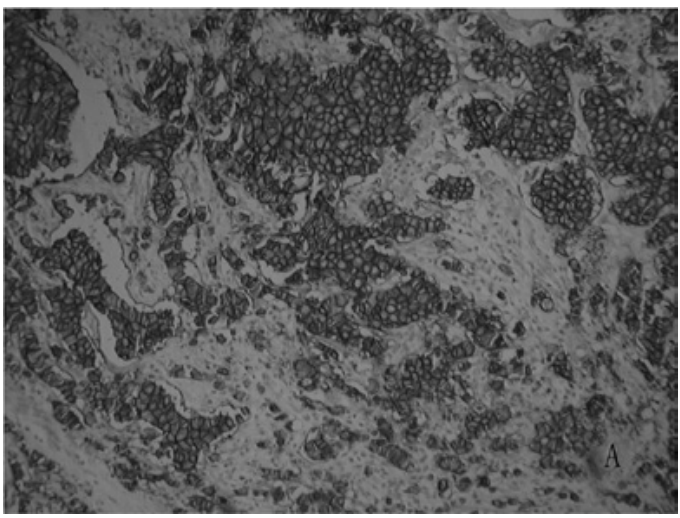

B

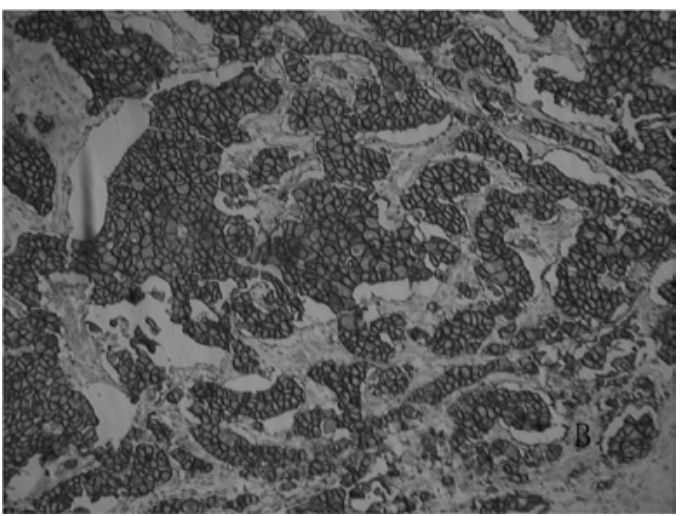

Figure 1. Comparison of the immunohistochemical HER2 staining of (A) primary breast cancer and (B) corresponding chest wall recurrence. Both (from the same patient) scored 3+ (magnification, $\mathrm{x} 40$ ).

Excluded cases. In 10 cases, no primary tumor blocks werefound in the specimen database, as these cases were previously treated at other hospitals. In another case, there were no tumor cells in the sections supposed to be recurrent breast cancer. Thus, 46 patient cases with local/regional recurrences were intitialy identified, but finally 35 cases with high-quality material of both primary tumors and the corresponding recurrences were investigated in the study.

\section{Results}

Table I shows the HER2 scores for the analyzed 35 primary breast cancers and the corresponding local-regional recurrences. HER2 overexpression (2+ or 3+) was found in $48.57 \%$ $(17 / 35)$ of the primary breast cancers and $45.71 \%(16 / 35)$ of the corresponding local-regional recurrences. There was a good agreement between the primary tumors and the paired asynchronous local-regional recurrences in the majority of cases.
A concordance of HER2 overexpression between the primary lesions and matching regional recurrences was observed in $85.71 \%$ of the breast cancer cases. Five changes were observed. However, there were only 3 patients who had HER 2 overexpression (all 3 cases had 2+ HER2 staining) in the primary tumors which changed to $1+$ in the chest wall recurrences; in another 2 patients, the score of $1+$ in the primary tumors switched to $2+$ or $3+$ in local-regional recurrences. Moreover, all cases with $3+$ HER 2 staining in the primary lesions retained HER2 overexpression in the recurrences. The major results from the HER2-score analyses are summarized in Tables II and III. Examples of staining patterns for a primary tumor and the corresponding metastases (which were both scored as 3+) are shown in Fig. 1A and B.

Two cases had both chest wall and supraclavicular recurrent samples. The same HER2 scores were noted between the chest wall and supraclavicular lesions; 1 case was scored as $2+$ and the other had negative staining. 


\section{Discussion}

Anti-HER2-targeted therapy, e.g., trastuzumab, for recurrent or metastatic breast cancer is generally thought to be reasonable when the primary lesions of the breast overexpress HER2 receptor. In several cases, however, the recurrent lesions show no response to trastuzumab treatment, even though the primary breast cancer exhibits strong HER2 expression (8). Heterogeneity of the receptor status in primary and metastatic breast cancer has been confirmed, and a loss of HER2 receptor in recurrent lesions, which may be affected by the intervening treatment, is known to be associated with a poor response to anti-HER2-targeted therapy. Yet, knowledge of HER2 expression in local-regional recurrences of breast cancer is relatively limited. For a receptor to be of interest for targeting, a similar expression in both the primary tumors and the disseminated lesions is required. Investigation of the concordance of the receptor status between recurrences or metastases and the primary tumors will provide valuable information on whether the receptor is suitable as a target for diagnostic and/or therapeutic procedures. In the present study, the expression of HER2 was investigated immunohistochemically in paired samples from a series of primary breast lesions and corresponding local-regional recurrences.

HER2 overexpression $(2+/ 3+)$ was found in $48.57 \%$ of the primary lesions and $45.71 \%$ of the local-regional recurrences. HER 2 expression in breast cancer has been commonly reported to range from 20 to $30 \%$ (12-14). Our result showed a higher percentage since our analyzed cases represented a more malignant subgroup which developed recurrences. Studies reporting a higher HER2 expression rate were also noted in the literature. Carlsson et al (17), using the same scoring criteria, found HER 2 expression in $55 \%$ of the analyzed primary breast cancers and lymph node metastases. Braun et al (24) reported HER 2 overexpression in $60 \%$ of breast cancers with bone marrow metastases.

Furthermore, a good agreement was noted between the primary tumors and the paired asynchronous recurrences in the majority of our studied cases. A concordance of HER2 overexpression between the primary lesions and matching regional recurrences was observed in $85.71 \%$ of the breast cancer cases. Previous studies mainly focused on the concordance of the HER 2 status between primary breast cancer and synchronous lymph node metastases, or between primary tumors and distant metastases, while reports concerning local-regional recurrences are relatively limited. The reported prevalence of concordance of the HER 2 status between primary tumors and synchronous lymph node metastases ranges from 82 to $94 \%(16,25)$, and that between primary tumors and distant metastases ranges from 92.4 to $97 \%(19,26,27)$. Our data of local-regional recurrences are consistent with these former findings; only 3 patients with HER 2 overexpression (scored as 2+) in the primary tumors had lower HER2 scores in the corresponding recurrences, and in another 2 patients the score of $1+$ in the primary tumors switched to $2+$ or $3+$ in the local-regional recurrences. Moreover, all cases with $3+$ HER 2 staining in the primary lesions retained HER2 overexpression in the recurrences.

Although trastuzumab-based therapy is commonly used to treat metastatic disease, HER2 status is generally evaluated in the primary lesions since, in most cases, the metastatic lesions are not removed or biopsied prior to treatment. With regards to more recent clinical trials $(8,28)$, only $50 \%$ of the metastatic breast cancer patients with HER 2 overexpression respond to trastuzumab treatment. There may be many reasons for the poor response to trastuzumab (29). One of the explanations may be the heterogeneity of expression of HER 2 between the primary lesions and metastatic tumors, as receptor characteristics change with time and may be affected by anticancer treatment. However, based on our result and other reports, it appears that heterogeneity is an unlikely explanation.

The HER2 is commonly expressed in breast cancer, and its expression in primary tumors and the corresponding recurrences was concordant in the majority of cases. Our results add to the body of data on the subject. As the receptor expression may lose or gain in recurrences at a probability of approximately $10 \%$, assessment of the receptor status in recurrent lesions is encouraged.

\section{Acknowledgements}

The authors acknowledge financial support from grants from the Science and Technology Project of Zhejiang (no. 2009C34018), the Outstanding Young Investigator fund from the Health Bureau of Zhejiang China (no. 2008QN020), and the National Natural Science Foundation of China to Q. Wei (no. 81071823).

\section{References}

1. Jemal A, Siegel R, Xu J and Ward E: Cancer statistics 2010. CA Cancer J Clin 60: 277-300, 2010.

2. Xiang YB, Zhang W, Gao LF, Liu ZW, Xu WH, Liu EJ and Ji BT: Methods for time analysis of cancer incidence rates. Chin J Epidemiol 25: 173-177, 2004.

3. Thomas ES, Gomez HL, Li RK, Chung HC, Fein LE, Chan VF, Jassem J, Pivot XB, Klimovsky JV, de Mendoza FH, Xu B, Campone M, Lerzo GL, Peck RA, Mukhopadhyay P, Vahdat LT and Roché HH: Ixabepilone plus capecitabine for metastatic breast cancer progressing after anthracycline and taxane treatment. J Clin Oncol 25: 5210-5217, 2007.

4. O'Shaughnessy J, Twelves C and Aapro M: Treatment for anthracycline-pretreated metastatic breast cancer. Oncologist 7 (Suppl 6): 4-12, 2002.

5. Bonneterre J, Buzdar A, Nabholtz JM, Robertson JF, Thürlimann B, von Euler M, Sahmoud T, Webster A, Steinberg M; Arimidex Writing Committee; Investigators Committee Members: Anastrozole is superior to tamoxifen as first-line therapy in hormone receptor positive advanced breast carcinoma. Cancer 92: 2247-2258, 2001.

6. Mouridsen H, Gershanovich M, Sun Y, Perez-Carrion R, Boni C, Monnier A, Apffelstaedt J, Smith R, Sleeboom HP, Jaenicke F, Pluzanska A, Dank M, Becquart D, Bapsy PP, Salminen E, Snyder R, Chaudri-Ross H, Lang R, Wyld P and Bhatnagar A: Phase III study of letrozole versus tamoxifen as first-line therapy of advanced breast cancer in postmenopausal women: analysis of survival and update of efficacy from the International Letrozole Breast Cancer Group. J Clin Oncol 21: 2101-2109, 2003.

7. Marty M, Cognetti F, Maraninchi D, Snyder R, Mauriac L, Tubiana-Hulin M, Chan S, Grimes D, Antón A, Lluch A, Kennedy J, O'Byrne K, Conte P, Green M, Ward C, Mayne K and Extra JM: Randomized phase II trial of the efficacy and safety of trastuzumab combined with docetaxel in patients with human epidermal growth factor receptor 2-positive metastatic breast cancer administered as first-line treatment: the M77001 Study Group. J Clin Oncol 23: 4265-4274, 2005.

8. Slamon DJ, Leyland-Jones B, Shak S, Fuchs H, Paton V, Bajamonde A, Fleming T, Eiermann W, Wolter J, Pegram M, Baselga J and Norton L: Use of chemotherapy plus a monoclonal antibody against HER 2 for metastatic breast cancer that overexpresses HER2. N Engl J Med 344: 783-792, 2001. 
9. Geyer CE, Forster J, Lindquist D, Chan S, Romieu CG, Pienkowski T, Jagiello-Gruszfeld A, Crown J, Chan A, Kaufman B, Skarlos D, Campone M, Davidson N, Berger M, Oliva C, Rubin SD, Stein S and Cameron D: Lapatinib plus capecitabine for HER2-positive advanced breast cancer. N Engl J Med 355: 2733-2743, 2006.

10. Dawood S, Broglio K, Gonzalez-Angulo AM, Buzdar AU, Hortobagyi GN and Giordano SH: Trends in survival over the past two decades among white and black patients with newly diagnosed stage IV breast cancer. J Clin Oncol 26: 4891-4898, 2008.

11. Press MF, Cordon-Cardo C and Slamon DJ: Expression of the HER-2/neu proto-oncogene in normal human adult and fetal tissues. Oncogene 5: 953-962, 1990.

12. Schechter AL, Stern DF, Vaidyanathan L, Decker SJ, Drebin JA, Greene MI and Weinberg RA: The neu oncogene: an erb-Brelated gene encoding a 185,000-Mr tumour antigen. Nature 312: 513-516, 1984

13. Zhang D, Salto-Tellez M, Do E, Putti TC and Koay ES: Evaluation of HER-2/neu oncogene status in breast tumors on tissue microarrays. Hum Pathol 34: 362-368, 2003.

14. Shimizu C, Fukutomi T, Tsuda H, Akashi-Tanaka S, Watanabe T, Nanasawa $\mathrm{T}$ and Sugihara K: c-erbB-2 protein overexpression and p53 immunoreaction in primary and recurrent breast cancer tissues. J Surg Oncol 73: 17-20, 2000

15. Vogel CL and Franco SX: Clinical experience with trastuzumab (herceptin). Breast J 9: 452-462, 2003.

16. Cho EY, Han JJ, Choi YL, Kim KM and Oh YL: Comparison of Her-2, EGFR and cyclin D1 in primary breast cancer and paired metastatic lymph nodes: an immunohistochemical and chromogenic in situ hybridization study. J Korean Med Sci 23: 1053-1061, 2008.

17. Carlsson J, Nordgren H, Sjöström J, Wester K, Villman K, Bengtsson NO, Ostenstad B, Lundqvist $\mathrm{H}$ and Blomqvist $\mathrm{C}$ : HER2 expression in breast cancer primary tumours and corresponding metastases. Original data and literature review. Br J Cancer 90: 2344-2348, 2004.

18. Tsutsui S, Ohno S, Murakami S, Kataoka A, Kinoshita J and Hachitanda Y: EGFR, c-erbB2 and p53 protein in the primary lesions and paired metastatic regional lymph nodes in breast cancer. Eur J Surg Oncol 28: 383-387, 2002.

19. Gancberg D, di Leo A, Cardoso F, Rouas G, Pedrocchi M, Paesmans M, Verhest A, Bernard-Marty C, Piccart MJ and Larsimont D: Comparison of HER-2 status between primary breast cancer and corresponding distant metastatic sites. Ann Oncol 13: 1036-1043, 2002.

20. Vincent-Salomon A, Jouve M, Genin P, Fréneaux P, Sigal-Zafrani B, Caly M, Beuzeboc P, Pouillart P and Sastre-Garau X: HER2 status in patients with breast carcinoma is not modified selectively by preoperative chemotherapy and is stable during the metastatic process. Cancer 94: 2169-2173, 2002.
21. Carlsson J, Forssell Aronsson E, Hietala SO, Stigbrand T and Tennvall J: Tumour therapy with radionuclides: assessment of progress and problems. Radiother Oncol 66: 107-117, 2003.

22. Wei Q, Sheng L, Shui Y, Hu Q, Nordgren H and Carlsson J: EGFR, HER2 and HER3 expression in laryngeal primary tumours and corresponding metastases. Ann Surg Oncol 15: 1193-1201, 2008.

23. Bilous M, Dowsett M, Hanna W, Isola J, Lebeau A, Moreno A, Penault-Llorca F, Rüschoff J, Tomasic G and van de Vijver M: Current perspectives on HER2 testing: a review of National Testing Guidelines. Mod Pathol 16: 173-182, 2003.

24. Braun S, Schlimok G, Heumos I, Schaller G, Riethdorf L, Riethmüller G and Pantel K: ErbB2 overexpression on occult metastatic cells in bone marrow predicts poor clinical outcome of stage I-III breast cancer patients. Cancer Res 61: 1890-1895, 2001.

25. Cardoso F, di Leo A, Larsimont D, Gancberg D, Rouas G, Dolci S, Ferreira F, Paesmans M and Piccart M: Evaluation of HER2, p53, bcl-2, topoisomerase II-alpha, heat shock proteins 27 and 70 in primary breast cancer and metastatic ipsilateral axillary lymph nodes. Ann Oncol 12: 615-620, 2001.

26. Thompson AM, Jordan LB, Quinlan P, Anderson E, Skene A, Dewar JA, Purdie CA; Breast Recurrence in Tissues Study Group: Prospective comparison of switches in biomarker status between primary and recurrent breast cancer: the Breast Recurrence In Tissues Study (BRITS). Breast Cancer Res 12: R92, 2010.

27. Tapia C, Savic S, Wagner U, Schönegg R, Novotny H, Grilli B, Herzog M, Barascud AD, Zlobec I, Cathomas G, Terracciano L, Feichter $\mathrm{G}$ and Bubendorf L: HER2 gene status in primary breast cancers and matched distant metastases. Breast Cancer Res 9: R31, 2007.

28. Untch M, Muscholl M, Tjulandin S, Jonat W, Meerpohl HG, Lichinitser M, Manikhas AG, Coumbos A, Kreienberg R, du Bois A, Harbeck N, Jackisch C, Müller V, Pauschinger M, Thomssen C, Lehle M, Catalani O and Lück HJ: First-line trastuzumab plus epirubicin and cyclophosphamide therapy in patients with human epidermal growth factor receptor 2-positive metastatic breast cancer: cardiac safety and efficacy data from the Herceptin, Cyclophosphamide, and Epirubicin (HERCULES) trial. J Clin Oncol 28: 1473-1480, 2010.

29. Spector NL and Blackwell KL: Understanding the mechanisms behind trastuzumab therapy for human epidermal growth factor receptor 2-positive breast cancer. J Clin Oncol 27: 5838-5847, 2009. 